\title{
Preventive Effect of Egg Membrane Protein Supplementation on Dragon Boat Sports Injury under the Monitoring of Artificial Intelligence and Big Data
}

\author{
Xianfang Shao $\mathbb{i D}^{1}$ and Wenping Ye $\mathbb{i D}^{2}$ \\ ${ }^{1}$ Institute of Physical Education, Hubei University of Science and Technology, Xianning 437100, Hubei, China \\ ${ }^{2}$ Institute of Physical Education, Huanggang Normal University, Huanggang 438000, Hubei, China \\ Correspondence should be addressed to Wenping Ye; 13871998420@163.com
}

Received 16 June 2021; Revised 16 July 2021; Accepted 13 August 2021; Published 23 October 2021

Academic Editor: Sang-Bing Tsai

Copyright (c) 2021 Xianfang Shao and Wenping Ye. This is an open access article distributed under the Creative Commons Attribution License, which permits unrestricted use, distribution, and reproduction in any medium, provided the original work is properly cited.

\begin{abstract}
Dragon boat is an excellent traditional national sport in China, with excellent fitness results. Based on the country's strong support for traditional national sports, the dragon boat has developed into a traditional national sport with specific influence and popularity among the masses. Eggshell membrane (ESM) has the effect of relieving arthritis, joint pain, and joint stiffness. The supplementary ESM's preventive effect on sports injuries has attracted people's attention. Based on this, this article builds a sports injury prediction model under artificial intelligence and big data monitoring to accurately predict the injuries suffered by athletes, provide help to reduce athletes' injuries during training, and promote the development of dragon boat sports. This article selects 20 members of a dragon boat team from a university and randomly divides them into a control group (supplement of equal amounts of whey protein), a normal group, an ESM low-dose group $(26 \mathrm{mg} / \mathrm{kg}$ bw/d), and an ESM high-dose group $(52 \mathrm{mg} / \mathrm{kg}$ bw/d), with 5 people in each group. The subjects were subjected to downhill exercise and immune stimulation experiments. Among them, the subjects in the control group performed downhill exercise for 12 hours, and they were tested for lactic acid (LAC), lactate dehydrogenase (LDH), urea, malondialdehyde (MDA), hemoglobin (Hb), blood creatinine (CRE), and other related physical and chemical indicators. The other three groups of subjects did not take low-dose and highdose ESM for 7 consecutive days and were injected with lipopolysaccharide on the 8th day for immune stimulation and tested for interferon $(\mathrm{IFN}-\gamma$ ), tumor necrosis factor (TNF- $\alpha$ ), interleukins (IL-1 $\beta$, IL-6, and IL-10), and other related cytokines. The results show that oral egg membrane protein (ESM) can reduce subjects' serum LAC, LDH, urea, MDA, Hb, and CRE concentration. In addition, the ESM can reduce the expression of proinflammatory factors IL- $1 \beta$ and TNF- $\alpha$, while increasing the expression of anti-inflammatory factor IL-10, which provides clinical data for the clinical use of ESM as a supplement for sports injury or for relieving arthritis symptoms. The study shows that egg membrane protein has a protective effect against sports injury and may be regulated by inflammatory factors.
\end{abstract}

\section{Introduction}

Sports injury usually occurs during intense or excessive exercise. Once a sports injury is caused, it will not only affect the physical condition of the athletes but also affect their mental health [1]. After the occurrence of sports injury, it generally depends on the self-healing of the damaged tissue, and the recovery generally depends on elastin and collagen in the tissue. At this time, athletes usually need to strengthen nutritional supplements, such as high-quality protein, e.g., soy protein and milk protein.
Egg membrane protein is a kind of egg inner membrane protein, which is rich in collagen and elastin, accounting for about $15 \%$, and the ratio of them is close to $1: 1$. After human digestion, it is easily converted into small molecular amino acids which are easy to be absorbed. They are also high-quality proteins. At the same time, egg membrane is a kind of traditional Chinese medicine, which has good medicinal and health value.

For the prevention and treatment of sports injury, the traditional methods are mainly anti-inflammatory and analgesic methods. At present, general methods of treating this type of disease include glucocorticoids, nonsteroidal anti- 
inflammatory drugs (such as ibuprofen and diclofenac), and biological agents (such as adalimumab and infliximab) [2]. It is worth pointing out that this type of medicine generally has a good effect, but it also has great side effects. Therefore, whether the selection of special nutritional supplements can achieve the effect of preventing and treating sports injuries remains to be further studied. In this paper, experimental studies are conducted to investigate the effect of ESM on skeletal muscle damage and exercise fatigue of subjects with overload exercise and to explore the possible mechanisms. This study can provide new ideas and directions for the follow-up study of eggshell membrane protein in the prevention of sports injuries.

\section{Related Overview}

2.1. Main Components and Functions of Eggshell. Eggshell is composed of a calcified shell and shell membrane, and the shell membrane includes inner and outer membranes. The purpose of these membranes is to retain protein and prevent bacterial infection. The main component of the shell membrane is protein, but it also contains a small amount of carbohydrates and lipids. The main component of egg membrane protein is type I collagen [3]. Eggshell membrane (ESM) is a kind of double-layer water-insoluble membrane, belonging to semipermeable membrane, which is divided into outer membrane and inner membrane. ESM is attached to an interwoven fiber network structure, and many tiny pores are distributed. These holes can be used for gas exchange [4]. The 3D structure of ESM is a network, which can be used to adsorb metal ions. The unique double-membrane structure of the eggshell membrane is mainly reflected in which the outer membrane contains a matrix to promote mineralization, while the inner membrane has substances to inhibit mineralization. This plays an essential role in the formation of eggshells of birds and reptiles in the process of biological evolution. Such a function enables the eggshell to complete mineralization in just 24 hours [5].

Compared with the eggshell, the eggshell membrane has a wider range of biological activities, and its main component is protein, which is similar to the composition of cell membrane proteins and exists in the form of glycoprotein [6]. The shell membrane contains about $90 \%$ protein, 3\% liposome, and $2 \%$ carbohydrate. Among them, proteins include keratin, collagen, and complex proteins. There is about $10 \%$ collagen in the shell membrane. Egg membrane protein also has many active substances, such as mucopolysaccharide, chondroitin sulfate, and hyaluronan. In addition, it also contains various enzymes and other bioactive ingredients. The ESM contains more than 200 species of proteins, which can not only resist the invasion of resistant pathogens but also have certain biomedical functions [4].

At present, researchers at home and abroad have applied ESM in the biomedical fields, such as wound healing and preparation of antibacterial materials. Zadik found that ESM can reduce the pain of the patients and accelerate the healing speed of the wound, so ESM can be regarded as the skin graft donor site dressing. Yang found that ESM can effectively promote the epithelialization of skin graft donor site and reduce the pain of patients. GO/ESM (graphene oxide/ eggshell membrane compliance material) can promote the proliferation of osteoblasts and promote bone biomineralization, so it can be used to prepare mineralized matrix materials [7].

2.2. Classification and Mechanism of Sports Injury. Sports injury is usually caused by direct contact between different parts of the body and the outside world or the muscles and joints of the body itself during the movement process due to the effect of force. Sprains, contusions, and abrasions are more common, and injuries to the viscera, brain, heart, kidney, liver, and other important organs sometimes occur. In terms of the nature of sports injuries, sports injuries are mainly periostitis, joint sprain, and muscle strain, while fractures, dislocations, and other injuries are less common [8].

For athletes, the internal factors related to sports ability, such as muscle contraction, oxygen transport and storage, material metabolism, and physiological function regulation, are directly related to proteins. In summary, the protein plays an important role in body weight control. The purpose of protein supplements for athletes is to promote the repair of skeletal muscle structure and functional recovery and improvement after exercise, increase muscle strength, increase muscle volume, maintain the positive nitrogen balance of exercise body, improve the release of energy utilization rate, and reduce the water equality of stress hormones. However, protein supplementation to improve athletes' athletic ability and promote athletic performance is influenced by many factors, such as athletic performance, intensity, duration, body energy metabolism, training level, athlete nutrition, and fitness [9].

2.3. Exercise and Protein Metabolism. The role of proteins in exercise is much more important than imagined, which is mainly reflected in the fact that the protein can promote the repair and recovery of skeletal muscle microstructure after exercise. The supplement of special proteins after exercise can stimulate the rapid resynthesis of muscle glycogen and create a stimulating hormone environment for skeletal muscle to promote anabolism. Moreover, adequate and high-quality protein nutrition combined with scientific strength training can maintain the body's positive nitrogen balance, promote muscle growth, and increase muscle strength [10]. In addition, during exercise, when the muscle glycogen reserve is sufficient, the protein energy supply accounts for about $5 \%$ of the total energy demand. If the muscle glycogen reserve is almost exhausted, the protein energy supply will increase to $10 \%-15 \%$. Of course, this also depends on the type of exercise, exercise intensity, and duration.

The effect of exercise on protein synthesis and catabolism is related to exercise intensity and time. Endurance exercise and short-term intense exercise can reduce protein synthesis and metabolism, while prolonged exercise and resistance exercise can speed up the rate of protein synthesis. The rate of protein synthesis in exercise is affected by exercise intensity and time. Exercise can stimulate skeletal muscle protein metabolism and is affected by exercise mode, 
intensity, and time. In the recovery period after exercise, the protein degradation of skeletal muscle gets gradually inhibited, and the synthesis and metabolism began to strengthen.

Taking a protein supplement as soon as possible after exercise has a positive effect on exercise ability. First, protein supplementation improves muscle energy dynamics; second, protein supplementation can inhibit the rise of stress hormones (such as cortisol); third, protein supplementation can delay the occurrence of exercise fatigue and maintain the integrity of muscle proteins; finally, protein supplementation can protect the function of the immune system [11].

2.4. Artificial Intelligence. The complex nervous system of the human body is built on hundreds of millions of neurons. Simulating the biological nervous system to build a neural network can help understand and obtain the information implicit in the data $[12,13]$. The output of the previous neuron is used as the input of the next neuron, and the weighted integration of the neuron is then input to the next neuron. Using artificial intelligence technology to monitor the data of athletes supplemented with egg membrane protein, the preventive effect of egg membrane protein supplementation on dragon boat sports injuries is analyzed. The forward transmission of neuron information can be represented as follows:

$$
y=f\left(w_{i} x_{i}+b\right) .
$$

Among them, $f$ represents the input signal, $b$ represents the bias part, $y$ represents the signal output. The commonly used activation function is the sigmoid function:

$$
f(x)=\frac{1}{1+\exp (x)} .
$$

The input data sequence can be denoted as $\left[x_{1}, x_{2}, x_{3}, \cdots\right]^{T} \in R^{n}$, and the output sequence is $\left[y_{1}, y_{2}, y_{3}, \cdots\right]^{T} \in R^{n}$. In order to obtain an accurate prediction model, the output sequence is compared with the target sequence to adjust the weight parameter $W$ and the bias vector $b$ of the model. Usually, the optimization goal can be set as error:

$$
E(x)=\frac{1}{2} \sum_{i=1}^{N}\left\|y_{i}\left(x_{i}\right)-y_{i}^{\prime}\left(x_{i}\right)\right\|^{2}
$$

Among them, $y_{i}\left(x_{i}\right)$ represents the output data, $y_{i}^{\prime}\left(x_{i}\right)$ represents the target data, and $N$ represents the number of data. In nonlinear classification, the mapping from the input feature space to the $k$-dimensional space is

$$
x \in R^{l} \longrightarrow y \in R^{k} \text {. }
$$

It can be realized by the inner product operation of the kernel function. The nonlinear mapping can still be classified by a hyperplane. Once the optimal hyperplane is calculated, the classification can be completed by using the following equation:

$$
g(x)=w^{T} x+w_{0}=\sum_{i=1}^{N_{s}} \lambda_{i} x_{i} x_{i}^{T} x+w_{0}
$$

Among them, $N_{s}$ represents the number of support vectors. The typical choice of a kernel function is

$$
\begin{aligned}
& k(x, z)=\left(x^{T} z+1\right)^{q}, \quad q>0, \\
& k(x, z)=\exp \left(\frac{-\|x-z\|^{2}}{\sigma^{2}}\right), \\
& k(x, z)=\tanh \left(\beta x^{T} z+\gamma\right) .
\end{aligned}
$$

After selecting a suitable kernel function and implicitly defining the mapping to a higher dimensional space, the Wolfe double optimization task becomes

$$
\max _{\lambda}\left(\sum_{i} \lambda_{i}-\frac{1}{2} \sum_{i, j} \lambda_{i} \lambda_{j} y_{i} y_{j} K\left(x_{i}, x_{j}\right)\right), \quad 0 \leq \lambda_{i} \leq C, i=1,2, \cdots, N .
$$

The resulting linear classification is as follows:

$$
\text { if } g(x)=\sum_{i=1}^{N_{s}} \lambda_{i} y_{i} K\left(x_{i}, x\right)+w_{0}>(<) 0, \quad \text { then } x \text { belongs to } w_{1}\left(w_{2}\right) \text {. }
$$

\section{Materials and Methods}

3.1. Experimental Animals and Methods. Here, we select 20 members of a dragon boat team from a university for testing. The average age of the subjects is 20.32 , the average height is
$178.27 \mathrm{~cm}$, and the average weight is $75.23 \mathrm{~kg}$. The subjects are divided into control group (supplements with equal amounts of whey protein; Shanghai Nuoshen Food Trading Co., Ltd.), normal group $(52 \mathrm{mg} / \mathrm{kg}$ bw/d, the dose used by subjects in this group is the same as the high-dose group, 
mainly for exhaustive training), ESM low-dose group $(26 \mathrm{mg} / \mathrm{kg}$ bw/d), and ESM high-dose group $(52 \mathrm{mg} / \mathrm{kg}$ bw/ d), with 5 people in each group, and egg membrane protein is continuously administered to assist training. The 20 athletes participating in the experiment used portable positioning systems, 3D gyroscopes, and 3D digital compass integrated equipment to collect exercise volume and exercise load data. Each athlete needs to bring equipment to collect exercise volume and exercise load during training. The relevant data of each athlete's exhaustion training are recorded, and the sports injury is predicted through each athlete's exercise volume, exercise load, body metabolism, and physical indicators.

\subsection{Determination of Amino Acids in Eggshell Membrane} Protein. Preparation of mixed solutions: smash the eggshell membrane through No. 3 sieve, weigh about $20 \mathrm{mg}$ sample into a $20 \mathrm{ml}$ hydrolysis tube, add $1 \mathrm{ml}$ of $6 \mathrm{~mol} / \mathrm{L}$ hydrochloric acid, and vacuumize under reduced pressure. To ensure that there is no oxygen residue in the decomposition tube, after replacing the nitrogen twice, vacuum again and seal. The hydrolysis tube was placed in a constant temperature drying oven at $100-102^{\circ} \mathrm{C}$ for $22 \mathrm{~h}$. Cooling, unsealing, and drying of solid at $60^{\circ} \mathrm{C}$ were performed. $2 \mathrm{ml}$ of $002 \mathrm{~mol} /$ $\mathrm{L}$ hydrochloric acid was dissolved again and then passed through a $002 \mu \mathrm{m}$ microporous membrane, and $400 \mathrm{~g} / \mathrm{L}$ filtrate was taken for standby.

Methods: ion exchange resin: $46 \mathrm{~mm} \times 60 \mathrm{~mm}, 2622 \mathrm{sc}$, Hitachi Co., Ltd.; buffer flow rate: $0.4 \mathrm{ml} / \mathrm{min}$; column pressure: $0.7700-0.73 \mathrm{MPa}$; ninhydrin flow rate: $035 \mathrm{ml} / \mathrm{min}$; column pressure: $0.700-0.80 \mathrm{MPa}$; column temperature: $54^{\circ} \mathrm{C}$; reactor temperature: $136.0^{\circ} \mathrm{C}$; and nitrogen pressure: $20 \mathrm{kPa}$.

\subsection{Sample Collection and Detection of Exercise Metabolism} Related Factors. After the experiment, $5 \mathrm{~mL}$ of intravenous blood were collected from the subjects (with the addition of coagulant), placed at room temperature for $0.5 \mathrm{~h}$, centrifuged for 15 minutes $(4000 \mathrm{rpm})$, and the serum was collected for use. The analysis kits for lactate dehydrogenase $(\mathrm{LDH})$, urea (BU), and malondialdehyde (MDA) were purchased from Nanjing Jiancheng Biological Co., Ltd., and the detection methods were carried out in accordance with the instructions.

\subsection{Immune Stimulation and Blood Collection and Detection} of Related Cytokines. In the immune stimulation experiment, the subjects were injected with a pyrogen-free lipopolysaccharide solution of $2.5 \mathrm{mg} / \mathrm{kg}$, and the control group was injected with physiological saline. The subjects were subjected to intravenous blood sampling on 8,21 , and 35 days. At the same time, intravenous blood sampling was performed $1.5 \mathrm{~h}, 3 \mathrm{~h}$, and $24 \mathrm{~h}$ after lipopolysaccharide (LPS) injection. The collected plasma is used for the detection of cytokines and is stored in an ultralow temperature freezer at $-80^{\circ} \mathrm{C}$. This study detected 5 cytokines, including interferon $(\mathrm{IFN}-\gamma)$, tumor necrosis factor (TNF- $\alpha$ ), and interleukins (IL-1 $\beta$, IL-6, and IL-10).
3.5. Data Statistics and Analysis. The data were analyzed by Excel and SPSS statistical software, and the results showed the mean \pm standard deviation. $T$-test was used for intergroup sampling. ${ }^{*} P<0.05$ indicates significant difference, and ${ }^{* *} P<0.01$ indicates extremely significant difference.

\section{Results and Analysis}

4.1. Analysis of Amino Acid Composition of Egg Membrane Protein. 19 kinds of amino acids were detected in eggshell membrane, including serine (Ser), glycine (Gly), methionine (Met), histidine (His), isoleucine (Ile), tryptophan (Tyr), phenylalanine (Phe), hydroxylysine (OH-Lys), hydroxyproline (OH-Pro), threonine (Thr), proline (Pro), cysteine (Cys), aspartic acid (Asp), lysine (Lys), leucine (Leu), valine (Val), glutamic acid (Glu), alanine (Ala), and arginine (Arg), which were the most abundant amino acids. The contents of glutamic acid (Glu), cysteine (Cys), and proline (Pro) accounted for $12.9 \%, 9.1 \%$, and $8.4 \%$, respectively. The content of hydroxyproline (OH-Pro) was $0.5 \%$ and $1.2 \%$, respectively, as shown in Table 1 and Figure 1.

4.2. Effects of ESM Supplementation $(52 \mathrm{mg} / \mathrm{kg} \mathrm{bw} / \mathrm{d})$ on Lactate (LAC), Lactate Dehydrogenase (LDH), Urea, and Malondialdehyde (MDA). After sport injury experiments, the concentrations of lactic acid (LAC), urea, and malondialdehyde (MDA) in serum supplemented with ESM $(52 \mathrm{mg} / \mathrm{kg} \mathrm{bw} / \mathrm{d}$ ) were found to be lower than those in the control group, and the difference was significant $(P<0.05)$. However, there was no significant difference in the concentration of lactate dehydrogenase (LDH) between the two groups $(P>0.05)$. Details are shown in Table 2 and Figure 2 .

4.3. Effects of Different Doses of ESM (Control Group, $26.0 \mathrm{mg} / \mathrm{kg} \mathrm{bw/d}$ or $52.0 \mathrm{mg} / \mathrm{kg} \mathrm{bw/d)}$ on Human Proinflammatory Cytokines. The results of the study showed that the five cytokines (IFN- $\gamma$, IL-1 $\beta$, IL-6, IL-10, and TNF- $\alpha$ ) maintained the original level of all cytokines, and there was no statistically significant difference (Table 3 and Figure 3 ).

After 7 consecutive days of low-dose ESM $(26.0 \mathrm{mg} / \mathrm{kg}$ bw/d), the mice were stimulated with lipopolysaccharide (LPS). The results showed that the cytokine IL- $1 \beta$ decreased by $43.7 \%(P=0.013)$ at $1.5 \mathrm{~h}, 28.8 \%(P=0.034)$ at $3 \mathrm{~h}$, and $20.8 \%(P=0.006)$ at $24 \mathrm{~h}$, respectively. Compared with the control group, IL-10 decreased by $27.6 \%(P=0.028)$ at $1.5 \mathrm{~h}$ and increased by $74.6 \%(P=0.097)$ at $24 \mathrm{~h}$. Other cytokines including IFN- $\gamma$, IL- 6 , and TNF- $\alpha$ decreased by $23.2 \%$, $14.6 \%$, and $19.3 \%$, respectively, at $1.5 \mathrm{~h}$. However, there was no statistical significance in the data statistics, which could be used as a reference (see Table 4 and Figure 4 for details).

After 7 consecutive days of high-dose ESM $(52.0 \mathrm{mg} / \mathrm{kg}$ bw/d), the mice were stimulated with lipopolysaccharide (LPS). The results showed that the cytokine IL- $1 \beta$ decreased by $39.4 \%(P=0.003)$ at $1.5 \mathrm{~h}, 23.9 \%(P=0.044)$ at $3 \mathrm{~h}$, and $9.3 \%(P=0.093)$ at $24 \mathrm{~h}$, respectively. Compared with the control group, IL-10 decreased by $29.8 \%(P=0.015)$ at $1.5 \mathrm{~h}$ and increased by $57.5 \%(P=0.021)$ at $24 \mathrm{~h}$. IFN $-\gamma$ decreased by $33.5 \%$ at $1.5 \mathrm{~h}(P=0.047)$. IL- 6 decreased by about $20 \%$ at 
Table 1: Amino acid composition of eggshell membrane.

\begin{tabular}{lc}
\hline Amino acid & Content $(\%)$ \\
\hline Glu & 12.9 \\
Pro & 9.1 \\
Cys & 8.4 \\
Val & 7.9 \\
Asp & 7.9 \\
Arg & 7.5 \\
Thr & 6.2 \\
Ser & 5.5 \\
Gly & 5.8 \\
Leu & 4.8 \\
Met & 4.8 \\
His & 4.3 \\
Ile & 3.6 \\
Lys & 3.1 \\
Ala & 2.5 \\
Tyr & 2.2 \\
Phe & 1.8 \\
OH-Pro & 1.2 \\
OH-Lys & 0.5 \\
\hline
\end{tabular}

$1.5 \mathrm{~h}$ and $3 \mathrm{~h}$. TNF- $\alpha$ decreased by $32.1 \%$ at $1.5 \mathrm{~h}$ and $17.2 \%$ at $3 \mathrm{~h}$, showing an overall downward trend, but there was no statistical significance (see Table 5 and Figure 5 for details).

In summary, these studies showed that the cytokine IL$1 \beta$ reduced at $1.5 \mathrm{~h}, 3 \mathrm{~h}$, and $24 \mathrm{~h}$ after the subjects in the lowdose ESM group were stimulated by lipopolysaccharide. The expression level of IL-10 decreased at $1.5 \mathrm{~h}$ (as shown in Figure 4). In the high-dose ESM group, after being stimulated by lipopolysaccharide, the expression of the cytokines IL- $1 \beta$, INF- $\gamma$, and TNF- $\alpha$ decreased after $1.5 \mathrm{~h}$, and the amount of IL- $1 \beta$ was reduced at $3 \mathrm{~h}$ and $24 \mathrm{~h}$. However, at $24 \mathrm{~h}$, there was a certain increase in IL-10 expression (as shown in Figure 5).

4.4. Effect of Supplementing ESM (52 $\mathrm{mg} / \mathrm{kg} \mathrm{bw/d})$ on Human Hemoglobin (Hb)/Blood Creatinine (CRE). Before the experiment, compared with the control group, the $\mathrm{Hb}$ of the subjects in the ESM-supplemented group had $P>0.05$, indicating that there was no significant difference in the $\mathrm{Hb}$ of the rats before the experiment; after the experiment, the $\mathrm{Hb}$ content of the subjects in the ESM-supplemented group was significantly higher than that of the control group; ${ }^{*} P<0.05$, the difference is significant, as shown in Table 6 .

Before the experiment, the CRE of the subjects in the ESM-supplemented group had $P>0.05$ compared with the control group, indicating that there was no significant difference in the CRE of the rats before the experiment; after the experiment, the CRE content of the subjects in the ESMsupplemented group increased significantly compared with the control group; ${ }^{* *} P<0.01$, the difference is clearly significant, as shown in Table 7.

4.5. Effects of ESM Supplementation on Glucuronidase Activity in Skeletal Muscle Tissue of Subjects Exercise. Glucuronidase activity decreased by $22.70 \%(P<0.05)$ immediately after exercise, $25.12 \%(P<0.05)$ at 12 hours after exercise, $33.33 \%(P<0.05)$ at 24 hours after exercise, and $44 \%(P<0.05)$ at 48 hours after exercise.

It was found that serum $\beta$-glucuronidase increased 5.69 times immediately after a centrifugal exercise, 3.5 times in the 12-hour group, 3 times in the 24-hour group, and 2.4 times in the 48 -hour group. The change of $\beta$-glucuronidase reached the peak immediately after exercise and then decreased, showing a recovery trend. After ESM supplementation, the serum $\beta$-glucuronidase activity increased by 4.35 times immediately after exercise, 2.64 times at 12 hours after exercise, 2 times at 24 hours after exercise, and 1.3 times at 48 hours after exercise. These results indicate that ESM supplementation can significantly reduce exercise-induced skeletal muscle microinjury and promote the repair of exercise-induced skeletal muscle microstructure injury, as shown in Figure 6.

\section{Discussion}

Sports injury can lead to local inflammatory reactions, such as joint swelling, synovial effusion, and joint stiffness. Moreover, inflammation is considered an important factor in the development of many diseases, such as arthritis. In clinical practice, a large number of immune cells, including macrophages and monocytes, secreted interleukin- $1 \beta$ (IL- $1 \beta$ ), and tumor necrosis factor (TNF- $\alpha$ ), were found in the synovium of patients with arthritis by immunohistochemical and histological observation. The secretion of these inflammatory factors can lead to local tissue necrosis, inhibit the synthesis of cartilage matrix, and increase the sensitivity of patients to pain. Therefore, in the treatment process, these factors are used as important targets for the treatment of such diseases, such as etanercept, adamab, and infliximab.

Egg membrane protein is a type of traditional Chinese medicine, also known as "Phoenix clothing." It can heal wounds, treat ulcers, and treat burns. Egg membrane protein is rich in amino acids, of which glutamic acid, cysteine, and proline are the most important. However, cysteine was not detected in egg membrane protein. Nevertheless, it has been reported that the protein composition of ESM was analyzed by LC-MS, and it was found that ESM is mainly composed of cysteine, which is consistent with the findings in this paper. Cysteine, lysine, and other amino acids are important antioxidant and detoxification components, which may be an important material basis for ESM to resist the entry of external microorganisms into eggs and an important material basis for anti-inflammatory activity.

The lactic acid in the muscle is mainly derived from the anaerobic metabolism of glucose in the muscle during exercise. When the body does a lot of and strenuous exercise, a lot of lactic acid gets easily accumulated in the muscles. The urea in the blood is produced in the process of protein metabolism, and its level can also reflect the body's exercise level and the degree of body damage. Subjects found through exercise injury experiments that supplementation of ESM $(52 \mathrm{mg} / \mathrm{kg} \mathrm{bw} /$ d) can effectively reduce the concentration of total lactic 


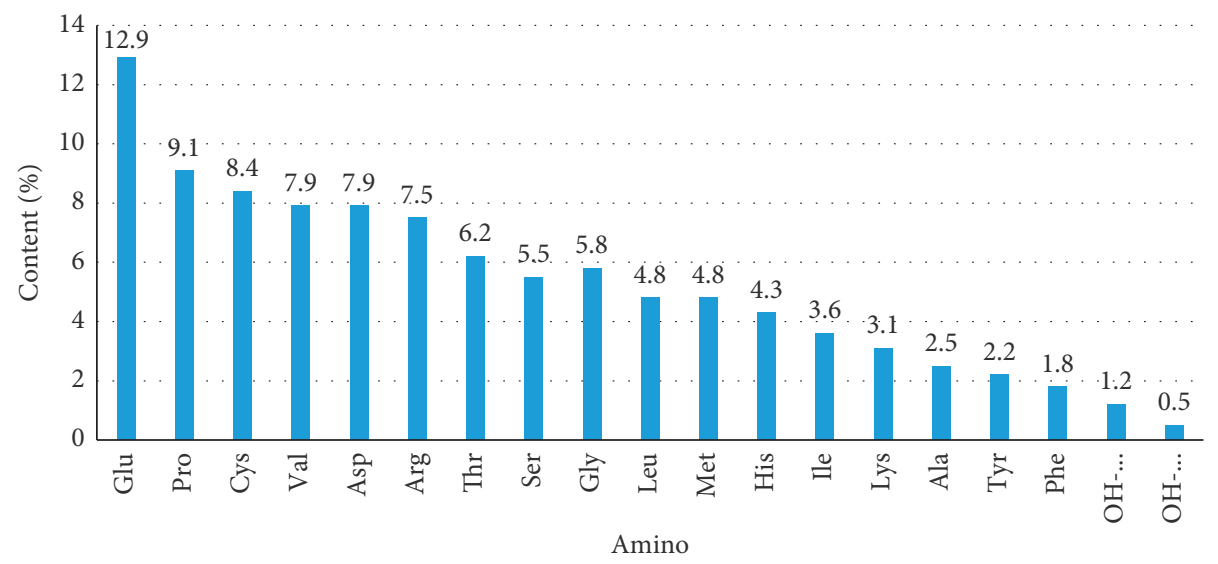

- Amino Content (\%)

FIgURe 1: Amino acid composition of eggshell membrane.

TABLE 2: LAC/urea/MDA/LDH changes in serum from rats.

\begin{tabular}{lcr}
\hline Index & Control & ESM $(52 \mathrm{mg} / \mathrm{kg})$ \\
\hline LAC $(\mathrm{nmol} / \mathrm{mL})$ & $6.355 \pm 1.431$ & $2.845 \pm 1.002^{* *}$ \\
Urea $(\mathrm{mmol} / \mathrm{L})$ & $3.454 \pm 0.945$ & $1.846 \pm 0.794^{* *}$ \\
MDA $(\mathrm{nmol} / \mathrm{mL})$ & $5.191 \pm 0.342$ & $3.755 \pm 1.221^{* *}$ \\
LDH $(\mathrm{mmol} / \mathrm{mL})$ & $40.342 \pm 16.154$ & $38.542 \pm 11.526$ \\
\hline
\end{tabular}

${ }^{* *} P<0.01$ compared with the control group, extremely significant difference; ${ }^{*} P<0.05$ compared with the control group, significant difference.

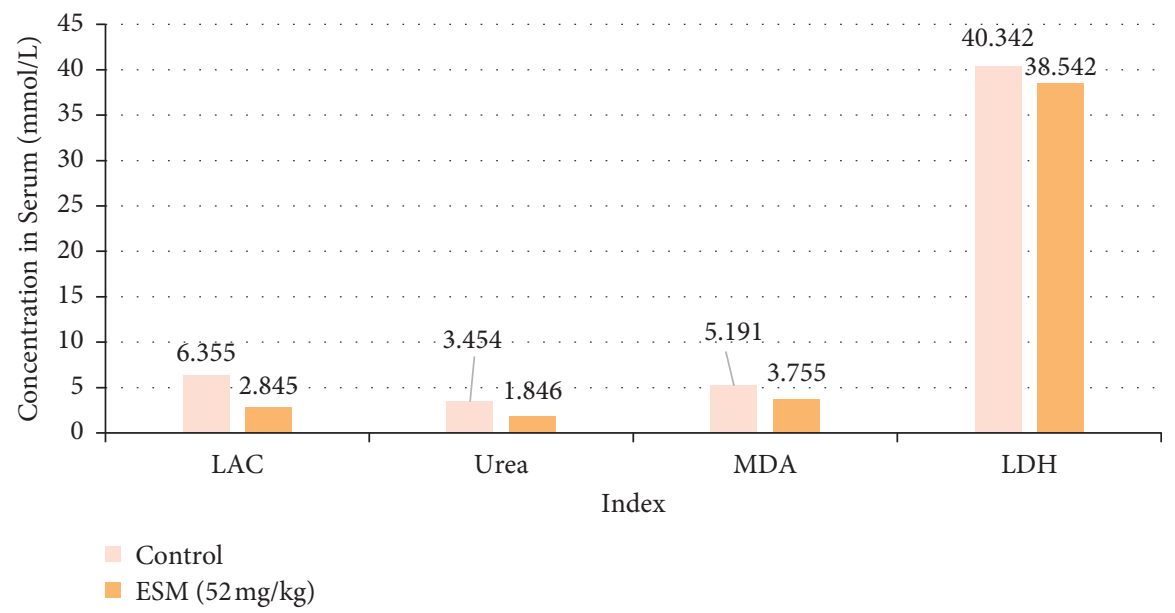

Figure 2: LAC/urea/MDA/LDH changes in serum from rats.

TABLE 3: Mean serum cytokine concentrations $(\mathrm{pg} / \mathrm{mL})$ in ESM-supplemented and control groups at baseline.

\begin{tabular}{lccc}
\hline & Control $(0 \mathrm{mg} / \mathrm{kg})$ & ESM $(26 \mathrm{mg} / \mathrm{kg})$ & ESM $(52 \mathrm{mg} / \mathrm{kg})$ \\
\hline IFN- $\gamma$ & $2.49 \pm 0.16$ & $2.40 \pm 0.00$ & $2.49 \pm 0.27$ \\
IL-1 $\beta$ & $15.8 \pm 10.0$ & $13.0 \pm 5.5$ & $18.6 \pm 13.2$ \\
TNF- $\alpha$ & $11.1 \pm 2.0$ & $10.2 \pm 0.7$ & $11.2 \pm 2.9$ \\
IL-6 & $9.80 \pm 0.00$ & $9.96 \pm 1.14$ & $10.2 \pm 1.1$ \\
IL-10 & $10.2 \pm 1.0$ & $9.80 \pm 0.00$ & $10.0 \pm 0.6$ \\
\hline
\end{tabular}

${ }^{* *} P<0.01$ compared with the control group, extremely significant difference; ${ }^{*} P<0.05$ compared with the control group, significant difference. 


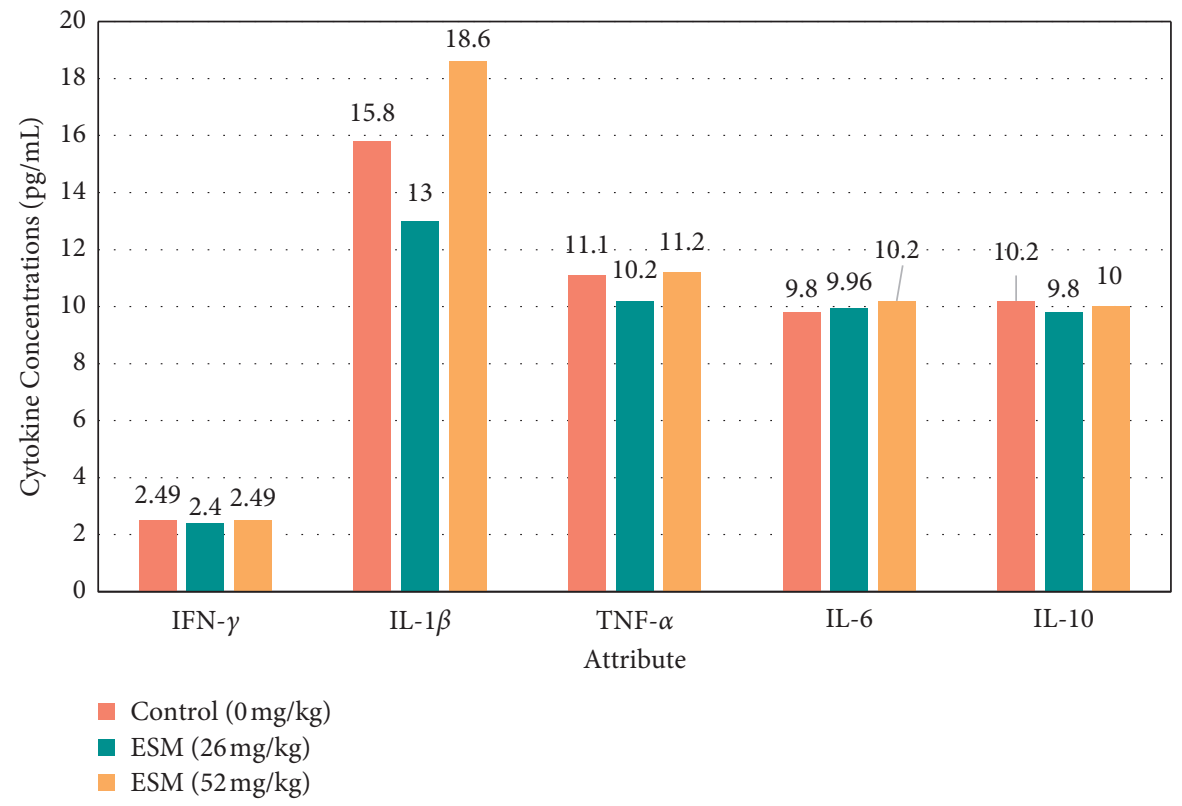

Figure 3: Mean serum cytokine concentrations (pg/mL) in ESM-supplemented and control groups at baseline.

TABLE 4: Change in mean serum cytokine concentrations $(\mathrm{pg} / \mathrm{mL})$ in 7 -day ESM-supplemented (26 mg/kg bw/d) and control groups from baseline at $1.5,3$, and 24 hours post-LPS treatment.

\begin{tabular}{|c|c|c|c|c|}
\hline & Hours posttreatment & $\begin{array}{c}\text { Control } \\
(0 \mathrm{mg} / \mathrm{kg}) \\
n=8\end{array}$ & $\begin{array}{c}\text { ESM } \\
(26 \mathrm{mg} / \mathrm{kg}) \\
n=8\end{array}$ & Difference (ESM vs. control) \\
\hline IFN- $\gamma$ & $\begin{array}{c}\text { Baseline } \\
1.5 \\
3 \\
24\end{array}$ & $\begin{array}{c}2.49 \pm 0.16 \\
6.35 \pm 2.48 \\
135 \pm 43 \\
3.55 \pm 2.18\end{array}$ & $\begin{array}{c}2.40 \pm 0.00 \\
4.88 \pm 2.60 \\
144 \pm 85 \\
2.49 \pm 0.14\end{array}$ & $\begin{array}{c}-3.5 \\
-23.2 \\
6.2 \\
-29.8\end{array}$ \\
\hline IL- $1 \beta$ & $\begin{array}{c}\text { Baseline } \\
1.5 \\
3 \\
24\end{array}$ & $\begin{array}{c}15.8 \pm 10.0 \\
62.4 \pm 17.1 \\
87.9 \pm 23.5 \\
12.6 \pm 2.1\end{array}$ & $\begin{array}{c}13.0 \pm 5.5 \\
35.1 \pm 16.7^{* *} \\
62.6 \pm 15.9^{* *} \\
9.96 \pm 0.42^{* *}\end{array}$ & $\begin{array}{c}-17.9 \\
-43.7^{* *} \\
-28.8^{* *} \\
-20.8\end{array}$ \\
\hline TNF- $\alpha$ & $\begin{array}{c}\text { Baseline } \\
1.5 \\
3 \\
24\end{array}$ & $\begin{array}{c}11.1 \pm 2.0 \\
1157 \pm 828 \\
84.5 \pm 46.7 \\
9.80 \pm 0.00\end{array}$ & $\begin{array}{c}10.2 \pm 0.7 \\
934 \pm 332 \\
75.5 \pm 28.7 \\
9.80 \pm 0.00\end{array}$ & $\begin{array}{c}-7.6 \\
-19.3 \\
-10.7 \\
0\end{array}$ \\
\hline IL-6 & $\begin{array}{c}\text { Baseline } \\
1.5 \\
3 \\
24\end{array}$ & $\begin{array}{c}9.80 \pm 0.00 \\
321 \pm 175 \\
386 \pm 172 \\
10.0 \pm 0.6\end{array}$ & $\begin{array}{c}9.96 \pm 1.14 \\
385 \pm 182 \\
329 \pm 133 \\
10.7 \pm 2.3\end{array}$ & $\begin{array}{c}1.7 \\
20 \\
-14.8 \\
6.6\end{array}$ \\
\hline IL-10 & $\begin{array}{c}\text { Baseline } \\
1.5 \\
3 \\
24\end{array}$ & $\begin{array}{c}10.2 \pm 1.0 \\
42.7 \pm 12.3 \\
18.7 \pm 5.6 \\
14.2 \pm 3.2\end{array}$ & $\begin{array}{c}9.80 \pm 0.00 \\
30.9 \pm 8.3^{* *} \\
19.3 \pm 7.4 \\
24.9 \pm 11.5^{*}\end{array}$ & $\begin{array}{c}-3.8 \\
-27.6^{* *} \\
3.1 \\
74.6^{*}\end{array}$ \\
\hline
\end{tabular}

${ }^{* *} P<0.01$ compared with the control group, extremely significant difference; ${ }^{*} P<0.05$ compared with the control group, significant difference.

acid and urea in the subjects' serum. It shows that ESM can reduce the injury caused by exercise. Although the concentration of lactate dehydrogenase in the blood did not decrease significantly, there was a tendency for its amount to decrease, indicating that ESM has the effect of reducing muscle damage. Malondialdehyde is also an indicator of the body's damage, which mainly reflects the degree of oxidation of the body's reception of free radicals and other factors [12]. Supplementing ESM $(52 \mathrm{mg} / \mathrm{kg}$ bw/d) can also effectively reduce the 


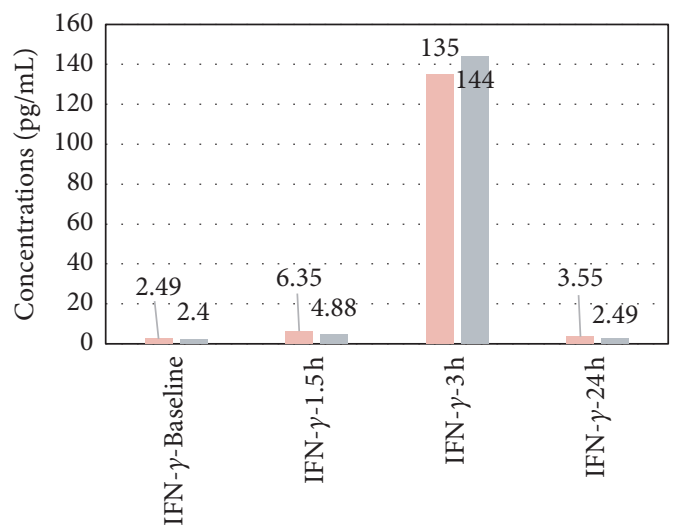

Attribute

- Control

- ESM $(26 \mathrm{mg} / \mathrm{kg})$

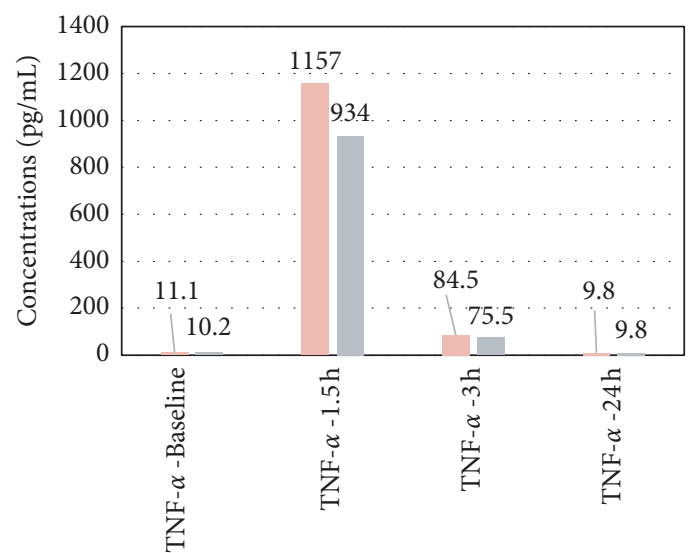

Attribute

- Control

- ESM $(26 \mathrm{mg} / \mathrm{kg})$

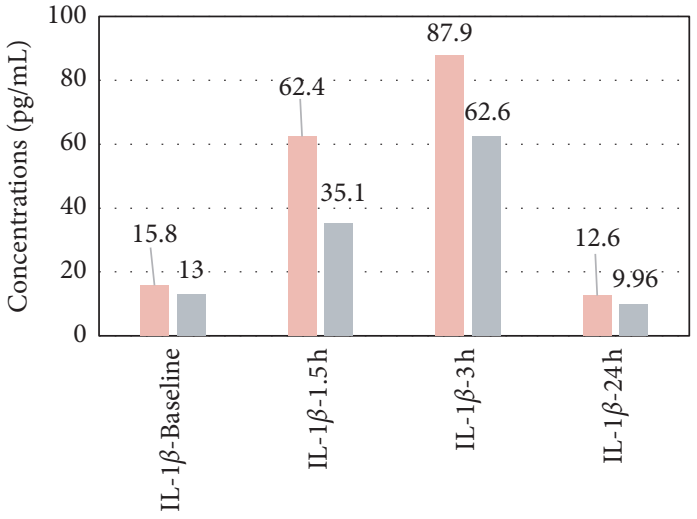

Attribute

- Control

ESM $(26 \mathrm{mg} / \mathrm{kg})$

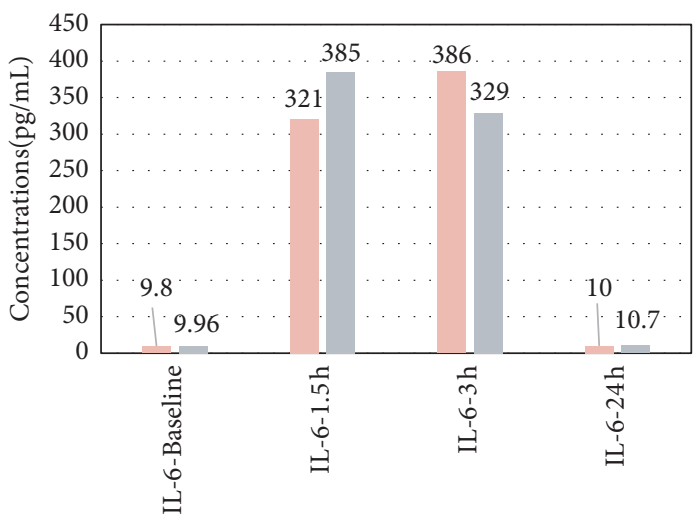

Attribute

Control

- ESM $(26 \mathrm{mg} / \mathrm{kg})$

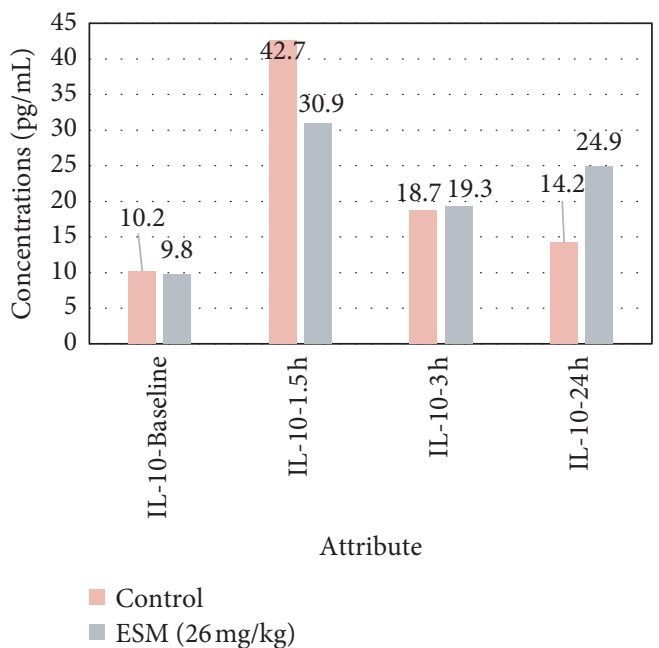

FIGURE 4: Change in mean serum cytokine concentrations $(\mathrm{pg} / \mathrm{mL})$ in 7 -day ESM-supplemented $(26 \mathrm{mg} / \mathrm{kg}$ bw/d) and control groups from baseline at $1.5,3$, and 24 hours post-LPS treatment. ${ }^{* *} P<0.01$ compared with the control group, extremely significant difference; ${ }^{*} P<0.05$ compared with the control group, significant difference. 
TABLE 5: Mean serum cytokine concentrations $(\mathrm{pg} / \mathrm{mL})$ in 7-day NEM-supplemented $(52 \mathrm{mg} / \mathrm{kg}$ bw/d) and control groups at baseline and $1.5,3$, and 24 hours post-LPS treatment.

\begin{tabular}{|c|c|c|c|c|}
\hline & Hours posttreatment & $\begin{array}{c}\text { Control } \\
(0 \mathrm{mg} / \mathrm{kg}) \\
n=8\end{array}$ & $\begin{array}{c}\text { NEM } \\
(52 \mathrm{mg} / \mathrm{kg}) \\
n=8\end{array}$ & $\%$ Difference (NEM vs. control) \\
\hline IFN- $\gamma$ & $\begin{array}{c}\text { Baseline } \\
1.5 \\
3 \\
24 \\
\end{array}$ & $\begin{array}{c}2.49 \pm 0.16 \\
6.35 \pm 2.48 \\
135 \pm 43 \\
3.55 \pm 2.18\end{array}$ & $\begin{array}{c}2.49 \pm 0.27 \\
4.22 \pm 0.76^{* *} \\
130 \pm 34 \\
2.82 \pm 0.75\end{array}$ & $\begin{array}{c}0.3 \\
-33.5^{* *} \\
-4.3 \\
-20.7 \\
\end{array}$ \\
\hline IL- $1 \beta$ & $\begin{array}{c}\text { Baseline } \\
1.5 \\
3 \\
24 \\
\end{array}$ & $\begin{array}{c}15.8 \pm 10.0 \\
62.4 \pm 17.1 \\
87.9 \pm 23.5 \\
12.6 \pm 2.1 \\
\end{array}$ & $\begin{array}{c}18.6 \pm 13.2 \\
37.8 \pm 9.7^{* *} \\
66.9 \pm 15.8^{* *} \\
11.4 \pm 1.2\end{array}$ & $\begin{array}{c}17.3 \\
-39.4^{* *} \\
-23.9^{* *} \\
-9.3^{*} \\
\end{array}$ \\
\hline TNF- $\alpha$ & $\begin{array}{c}\text { Baseline } \\
1.5 \\
3 \\
24 \\
\end{array}$ & $\begin{array}{c}11.1 \pm 2.0 \\
1157 \pm 828 \\
84.5 \pm 46.7 \\
9.80 \pm 0.00\end{array}$ & $\begin{array}{c}11.2 \pm 2.9 \\
786 \pm 161 \\
70.0 \pm 15.0 \\
9.80 \pm 0.00 \\
\end{array}$ & $\begin{array}{c}1.5 \\
-32.1 \\
-17.2 \\
0 \\
\end{array}$ \\
\hline IL-6 & $\begin{array}{c}\text { Baseline } \\
1.5 \\
3 \\
24\end{array}$ & $\begin{array}{c}9.80 \pm 0.00 \\
321 \pm 175 \\
386 \pm 172 \\
10.0 \pm 0.6\end{array}$ & $\begin{array}{c}10.2 \pm 1.1 \\
256 \pm 83 \\
306 \pm 64 \\
10.3 \pm 1.4\end{array}$ & $\begin{array}{c}4 \\
-20.1 \\
-20.6 \\
3 \\
\end{array}$ \\
\hline IL-10 & $\begin{array}{c}\text { Baseline } \\
1.5 \\
3 \\
24\end{array}$ & $\begin{array}{c}10.2 \pm 1.0 \\
42.7 \pm 12.3 \\
18.7 \pm 5.6 \\
14.2 \pm 3.2\end{array}$ & $\begin{array}{c}10.0 \pm 0.6 \\
30.0 \pm 8.1^{* *} \\
18.1 \pm 3.4 \\
22.4 \pm 6.1^{* *}\end{array}$ & $\begin{array}{c}-1.8 \\
-29.8^{* *} \\
-3.6 \\
57.5^{* *}\end{array}$ \\
\hline
\end{tabular}

${ }^{* *} P<0.01$ compared with the control group, extremely significant difference; ${ }^{*} P<0.05$ compared with the control group, significant difference.

concentration of total malondialdehyde CK in the subjects' serum, indicating that ESM can play an antioxidant effect in the body and protect the body from free radical damage. Glucuronidase is a type of glycoprotein, which is generally present in mammalian lysosomes and has a hydrolytic effect. When the body receives external stimuli and other inflammatory reactions, such as tissue necrosis, tissue disease, or tumors, the activity of glucuronidase will increase [13]. Studies have found that when the body is injured by sports, its skeletal muscle glucuronidase activity increases [14]. This study found that the glucuronidase activity of subjects in the $52 \mathrm{mg}$ / $\mathrm{kg}$ ESM supplementation group was significantly lower than that of the control group, indicating that ESM has a protective effect on sports injury. Supplementing ESM can reduce the values of $\mathrm{Hb}$ and $\mathrm{CRE}$ of subjects, further indicating that ESM has a protective effect on sports injury.

It has been reported that egg membrane protein can reduce the secretion of proinflammatory agents in immune cells in vitro, such as tumor necrosis factor (TNF- $\alpha$ ) [14]. The data of this study support that egg membrane protein can reduce the expression of proinflammatory factors, such as interleukin-1 $\beta$ (IL-1 $\beta)$ and tumor necrosis factor (TNF- $\alpha$ ) in vivo. Interestingly, under normal circumstances, egg membrane protein can promote the expression of inflammatory factors, but once stimulated by lipopolysaccharide, the expression of inflammatory factors changes. IL-10 is a known interleukin that can inhibit IL-1 $\beta$ and TNF- $\alpha$. Clinically, the expression of IL-10 in the articular cartilage of patients with arthritis is higher than that in normal tissues. This may be a self-protection mechanism of the body [15], that is, to combat the proinflammatory factors produced by the body.

It is worth pointing out that, in our preliminary experiments, we found that low-dose ESM combined with LPS stimulation cannot effectively promote the secretion of inflammatory factors. However, when the amount of gavage we gave the subjects increased to $26 \mathrm{mg} / \mathrm{kg}$ bw/d, the expression of the inflammatory factors IL- $1 \beta$ and IL-10 of the subject changed. This dosage is converted into a healthy adult $(60 \mathrm{~kg})$ dosage of approximately $0.25 \mathrm{~g} / \mathrm{kg}$ bw $/ \mathrm{d}$, which also provides certain information for our clinical dosage. In the two-dose inflammatory response model of ESM, the expression of proinflammatory factor IL- $1 \beta$ was significantly reduced within 24 hours (the reduction was about $20 \%-$ $45 \%)$. The expression of TNF- $\alpha$ also showed a certain downward trend, although there was no statistically significant difference. After immunostimulation, IL-10 showed a significant decrease $(27.6 \%-29.8 \%)$ at the beginning, but a significant increase $(57.5 \%-74.6 \%)$ was found within 24 hours. This shows that ESM can reduce the expression of proinflammatory factors IL- $1 \beta$ and TNF- $\alpha$, while increasing the expression of anti-inflammatory factor IL-10, which provides clinical data for the clinical use of ESM as a supplement for sports injury or for relieving arthritis symptoms.

\section{Conclusion}

This article analyzes the characteristics and causes of sports injuries of dragon boat athletes and sets out a simple model for predicting sports injuries under artificial intelligence and large data monitoring. The selection of data fitting methods 


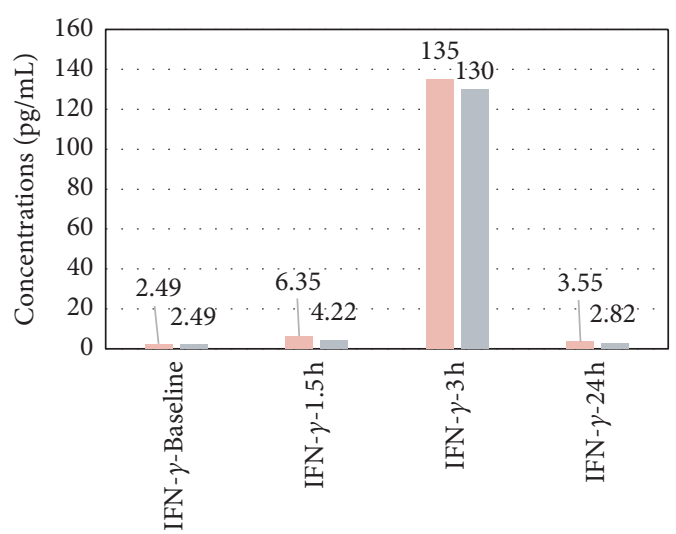

Attribute

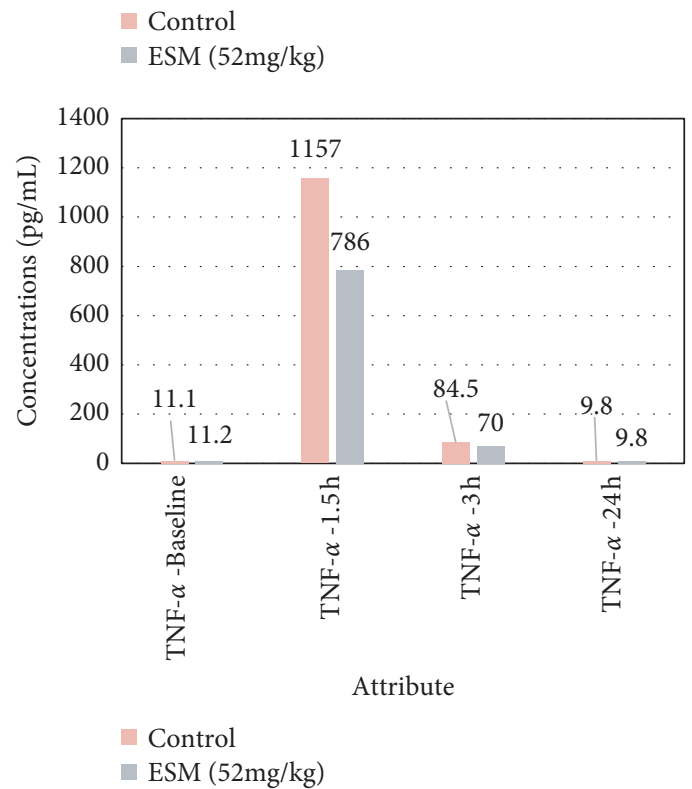

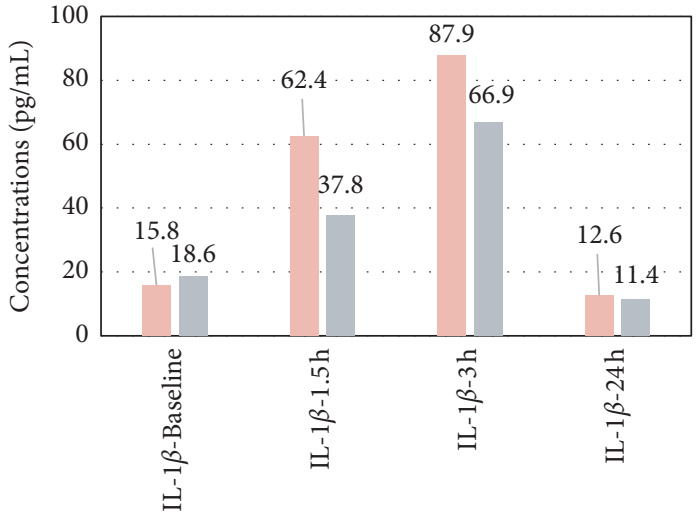

Attribute

- Control

ESM $(52 \mathrm{mg} / \mathrm{kg})$

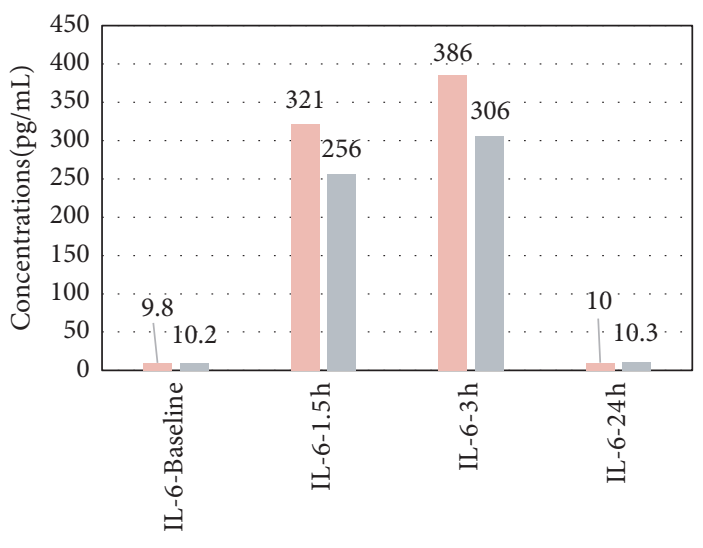

Attribute

Control

$\operatorname{ESM}(52 \mathrm{mg} / \mathrm{kg})$

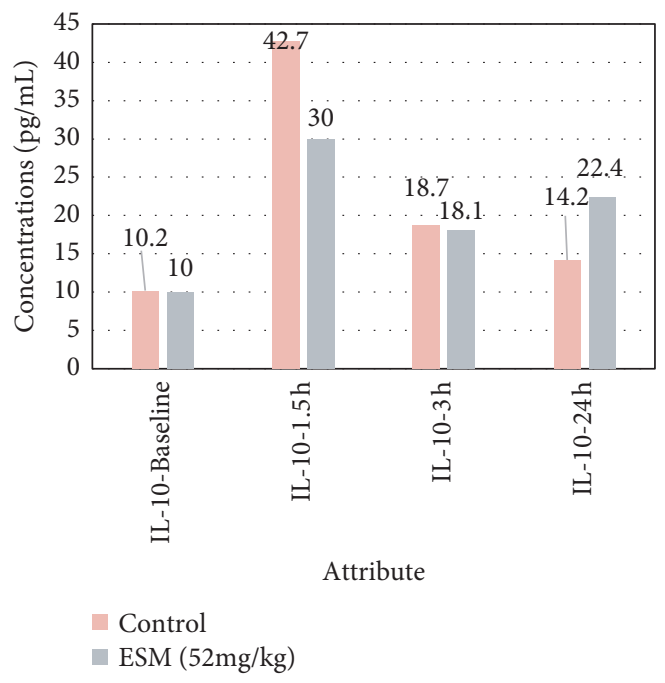

FiguRE 5: Mean serum cytokine concentrations $(\mathrm{pg} / \mathrm{mL})$ in 7 -day NEM-supplemented $(52 \mathrm{mg} / \mathrm{kg}$ bw/d) and control groups at baseline and $1.5,3$, and 24 hours post-LPS treatment. ${ }^{*} P<0.01$ compared with the control group, extremely significant difference; ${ }^{*} P<0.05$ compared with the control group, significant difference. 
TABLE 6: Experiment showing effects of ESM supplementation on $\mathrm{Hb}$ of rats.

\begin{tabular}{lcc}
\hline Index & Before & After \\
\hline Control & $153.78 \pm 1.21$ & $133.56 \pm 0.53$ \\
ESM $(52 \mathrm{mg} / \mathrm{kg})$ & $153.55 \pm 1.21$ & $148.45 \pm 1.12^{*}$ \\
\hline
\end{tabular}

${ }^{* *} P<0.01$ compared with the control group, extremely significant difference; ${ }^{*} P<0.05$ compared with the control group, significant difference.

TABLE 7: Experiment showing effects of ESM supplementation on CRE of rats.

\begin{tabular}{lrr}
\hline Index & Before & After \\
\hline Control & $143.78 \pm 1.21$ & $233.56 \pm 0.53$ \\
CRE $(\mu \mathrm{mol} / \mathrm{dL})$ & $143.44 \pm 0.95$ & $188.86 \pm 0.74^{* *}$ \\
\hline
\end{tabular}

${ }^{* *} P<0.01$ compared with the control group, extremely significant difference; ${ }^{*} P<0.05$ compared with the control group, significant difference.

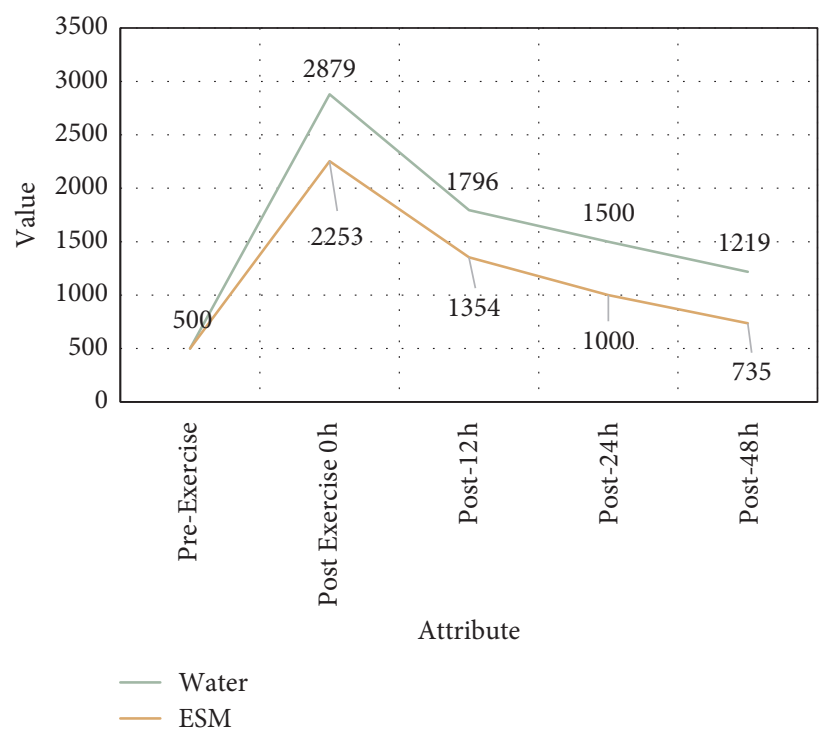

FIgURE 6: Effects of ESM supplementation on serum $\beta$-glucuronidase activity following a bout of eccentric exercise.

is to fully consider the complexity of sports injuries and influencing factors. The relationship was finally determined. This article uses the high-dose group of subjects through sports injury experiments and found that supplementation of ESM $(52 \mathrm{mg} / \mathrm{kg}$ bw/d) can effectively reduce the subjects' serum total lactic acid, urea, hemoglobin, blood creatinine, and malondialdehyde concentrations. ESM can protect the body from damage; supplementation of ESM can significantly reduce sports skeletal muscle microdamage and promote the repair of sports skeletal muscle microstructure damage. At the same time, ESM can reduce the expression of proinflammatory factors IL- $1 \beta$ and TNF- $\alpha$ subjected to immune stimulation, while increasing the expression of antiinflammatory factor IL-10, which indicates that the protective effect of ESM on the body may be mainly to reduce the expression of proinflammatory factors and increase the expression of anti-inflammatory factors. Boldly take the effect of egg membrane protein supplementation on sports injury through artificial intelligence preprocessing, extract features, and classify to achieve prediction results. All these provide basic information for ESM's application in sports injury protection or arthritis dietary supplements.

\section{Data Availability}

The data that support the findings of this study are available from the corresponding author upon reasonable request.

\section{Disclosure}

The authors confirm that the content of the manuscript has not been published or submitted for publication elsewhere.

\section{Conflicts of Interest}

The authors declare that there are no potential conflicts of interest.

\section{Authors' Contributions}

All authors have seen the manuscript and approved to submit it. 


\section{References}

[1] J. J. Harringman, J. Ludikhuize, and P. P. Tak, "Chemokines in joint disease: the key to inflammation," Annals of the Rheumatic Diseases, vol. 63, no. 3, pp. 1186-1194, 2014.

[2] J. Martel-Pelletier, N. Alaaeddine, and J. P. Pelletier, "Cytokines and their role in the pathophysiology of osteoarthritis," Frontiers in Bioscience, vol. 4, no. 1, pp. 694-703, 2019.

[3] M. Feldmann and R. N. Maini, "Role of cytokines in rheumatoid arthritis: an education in pathophysiology and therapeutics," Immunological Reviews, vol. 223, no. 2, pp. 7-19, 2018.

[4] H. Kokkonen, I. Soderstrom, J. Rocklov, G. Hallmans, K. Lejon, and S. R. Dahlqvist, "Up-regulation of cytokines and chemokines predates the onset of rheumatoid arthritis," Arthritis \& Rheumatism, vol. 62, no. 1, pp. 383-391, 2016.

[5] E. H. S. Choy and G. S. Panayi, "Cytokine pathways and joint inflammation in rheumatoid arthritis," New England Journal of Medicine, vol. 344, no. 3, pp. 907-916, 2018.

[6] F. M. Brennan and I. B. McInnes, "Evidence that cytokines play a role in rheumatoid arthritis," Journal of Clinical Investigation, vol. 118, no. 4, pp. 3537-3545, 2018.

[7] W. G. Dixon, S. Suissa, and M. Hudson, "The association between systemic glucocorticoid therapy and the risk of infection in patients with rheumatoid arthritis: systematic review and meta-analyses," Arthritis Research and Therapy, vol. 13, no. 2, p. 139, 2017.

[8] G. Singh, O. Wu, P. Langhorne, and R. Madhok, "Risk of acute myocardial infarction with nonselective non-steroidal antiinflammatory drugs: a meta-analysis," Arthritis Research and Therapy, vol. 8, no. 1, pp. 153-162, 2016.

[9] E. L. Masso Gonzalez, P. Patrignani, S. Tacconelli, and L. A. Garcia Rodriguez, "Variability among nonsteroidal antiinflammatory drugs in risk of upp: er gastrointestinal bleeding," Arthritis \& Rheumatism, vol. 62, no. 3, pp. 15921601, 2019.

[10] C. K. O’Neil, J. T. Hanlon, and Z. A. Marcum, “Adverse effects of analgesics commonly used by older adults with osteoarthritis-focus on non-opioid and opioid analgesics," The American Journal of Geriatric Pharmacotherapy, vol. 10, no. 1, pp. 331-342, 2019.

[11] K. J. Ruff, A. Winkler, R. W. Jackson, D. P. DeVore, and B. W. Ritz, "Eggshell membrane in the treatment of pain and stiffness from osteoarthritis of the knee: a randomized, multicenter, double-blind, placebo-controlled clinical study," Clinical Rheumatology, vol. 28, no. 2, pp. 907-914, 2019.

[12] Z. Lv, R. Lou, J. Li, A. K. Singh, and H. Song, "Big data analytics for $6 \mathrm{G}$ enabled massive Internet of Things," IEEE Internet of Things Journal, vol. 99, no. 1, 2021.

[13] M. Abdel-Basset, M. El-hoseny, A. Gamal, and F. Smarandache, "A novel model for evaluation hospital medical care systems based on plithogenic sets," Artificial Intelligence in Medicine, vol. 100, no. 9, Article ID 101710, 2019.

[14] K. J. Ruff, D. P. DeVore, M. D. Leu, and M. A. Robinson, "Eggshell membrane: a possible new natural therapeutic for joint and connective tissue disorders. Results from two openlabel human clinical studies," Clinical Interventions in Aging, vol. 4, no. 3, pp. 235-240, 2019.

[15] M. Wong, M. J. C. Hendrix, K. von der Mark, C. Little and, and R. Stern, "Collagen in the egg shell membranes of the hen,” Developmental Biology, vol. 104, no. 1, pp. 28-36, 2018.
[16] J. R. Baker and D. A. Balch, "A study of the organic material of hen's-egg shell," Biochemical Journal, vol. 82, no. 4, pp. 352-361, 2017.

[17] K. F. Benson, K. J. Ruff, and G. S. Jensen, "Effects of natural eggshell membrane (nem) on cytokine production in cultures of peripheral blood mononuclear cells: increased supp: ression of tumor necrosis factor- $\alpha$ levels after in vitro digestion," Journal of Medicinal Food, vol. 15, no. 2, pp. 360-368, 2018. 